\title{
LAS EDICIONES DE POMPONIO MELA EN ESPAÑA: ANÁLISIS DE LA TRADICIÓN INCUNABLE ${ }^{1}$
}

\author{
MARÍA José CARRIZo Gómez \\ mjcarrizo@gmail.com
}

\section{RESUMEN}

El objeto de este artículo es analizar el patrimonio de la tradición incunable de la Cosmographia de Pomponio Mela conservado en España, centrando la atención en el examen de los ejemplares que se encuentran en fondos bibliográficos españoles con el fin de esclarecer la difusión y las modalidades de recepción de la obra de Mela en España.

Palabras Clave: Pomponio Mela; Cosmographia; incunables; recepción en España.

\section{Abstract}

The purpose of this paper is to analyze the heritage of Pomponio Mela's Cosmographia incunable tradition preserved in Spain, focusing on the revision of the copies which are kept in Spanish bibliographic reserved collections in order to clarify the diffusion and the different ways of reception of Mela's work in Spain.

KeY WORDS: Pomponio Mela; Cosmographia; incunabula; reception in Spain.

\footnotetext{
${ }^{1}$ Este trabajo forma parte de las actividades del Proyecto de Investigación financiado FFI2011-23685 «Estudio filológico de los textos clásicos latinos transmitidos en impresos incunables y postincunables conservados en España», que se desarrolla en el Departamento de Filología Clásica de la Universidad Nacional de Educación a Distancia, dirigido por D. Antonio Moreno Hernández, a quien agradezco la inestimable ayuda y el constante apoyo para la elaboración de este trabajo.
} 


\section{INTRODUCCIÓN}

El propósito fundamental de este artículo es realizar un análisis del corpus de ediciones incunables de la Cosmographia de Pomponio Mela conservadas en bibliotecas e instituciones españolas. La importancia de este patrimonio se ve avalada por el hecho de que España es el único país, fuera de Italia, donde se edita la obra de Mela en periodo incunable, en Valencia en el año 1482 y en Salamanca en el 1498.

Los primeros intentos de acercamiento a este corpus de ediciones se remontan a finales del siglo XIX y comienzos del XX gracias a Menéndez Pelayo (1902: 162-163) y Haebler (1903: 262-263). Ambos identifican las dos ediciones que se hacen en España de la obra de Mela y encuentran varios ejemplares de una y otra ${ }^{2}$.

Sin embargo, a lo largo del siglo XX nuestro conocimiento de las ediciones realizadas en el siglo XV se ha visto enriquecido gracias a los avances en los estudios de bibliofilia e incunabulística y a la elaboración de catálogos. Por este motivo, ahora contamos con herramientas ${ }^{3}$ para analizar más a fondo el bagaje de nuestro autor. Asimismo, el rastreo de los fondos de las bibliotecas aporta todavía ejemplares que hasta el momento no se encontraban registrados en los catálogos, como así se demostrará en este artículo.

\section{Aproximación a la historia de la transmisión del teXto de Mela}

Antes de adentrarnos en la revisión de los ejemplares incunables conservados en nuestro país, consideramos conveniente realizar una aproximación a la tradición manuscrita de la Cosmographia. El primer dato sobre la transmisión de esta obra se remonta a la Antigüedad Tardía, concretamente a la copia realizada en torno al siglo VI d. C. por Rusticio Helpidio Domnulo ${ }^{4}$, como han corroborado los estudios de Barlow (1938: 87-142) y Billa-

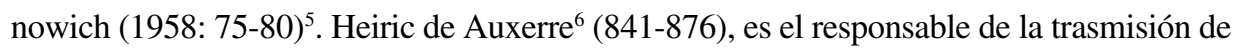

\footnotetext{
${ }^{2}$ Menéndez Pelayo revela que son seis los ejemplares incunables de la Cosmographia conservados en España: tres ejemplares de la edición de Valencia 1482 y otros tres de la edición de Salamanca 1498. De la edición de Valencia 1482, aseguraba que un ejemplar se encontraba en la Biblioteca Nacional, otro estaba en posesión de D. Fernando José Velasco y otro poseía D. Rafael Floranes, ejemplar que habría pertenecido a Nebrija. En cuanto a los ejemplares de la edición de Salamanca 1498, afirmaba que uno se encontraba en la Biblioteca de la Historia, otro pertenecía a D. Rafael Floranes y otro a D. Gregorio Mayans y Siscar. Por su parte, Haebler expone que son cinco los ejemplares de la obra de Mela conservados en España: dos de la edición de Valencia 1482 y tres de la de Salamanca 1498. Los ejemplares conservados de la edición de Valencia 1482 son, según este autor, el de la Biblioteca Nacional de Madrid y el de la Biblioteca de Toledo. De la edición de Salamanca 1498 da noticia de conservación de ejemplares en la Biblioteca Nacional de Madrid, en la Biblioteca Colombina de Sevilla y en la Biblioteca del Cabildo de Toledo.

${ }^{3}$ Entre los proyectos globales de catálogos del patrimonio incunabulístico hay que destacar el Gesamtkatalog der Wiegendrucke (GW) y el Incunable Short Title Catalogue (ISTC); en nuestro país contamos con la preciada herramienta del Catálogo Público del Patrimonio Bibliográfico Español (CCPBE).

${ }^{4}$ Cameron (2011: 449-450).

5 Además de la obra de Mela, también llevan la suscripción de Rusticio Helpidio Domnulo el epítome de Julio Paris del Factorum et dictorum memorabilium de Valerio Máximo y el De fluminibus de Vibio Secuestre.

${ }^{6}$ GuZmán Arias (1989: 14).
} 
la pequeña enciclopedia de Helpidio a la posteridad ya que copia y anota en Auxerre entre 860 y 862 el contenido ${ }^{7}$ del actual ms. Vaticanus Latinus $4929\left(\mathbf{V}^{8}\right)$.

Si bien la trayectoria de $\mathbf{V}$ desde Rávena hasta Auxerre no nos es conocida, a partir del siglo IX se pueden rastrear sus pasos con mayor precisión ${ }^{9}$. La Cosmographia de $\mathbf{V}$ fue utilizada en la segunda mitad del siglo IX por el autor anónimo del De situ orbis (Leiden, Voss. lat. F.113) que trabajó en Auxerre ${ }^{10}$. Hacia el siglo X, el ms. V se encuentra en Orleans. Aquí se le hacen distintas y numerosas anotaciones a principios del siglo XII. A mitad de este siglo el texto de Julio Paris es extraído en Orleans en una copia conservada en el ms. Vaticano Pal. lat. 957. La continuada presencia de V en Orleans está atestiguada en el siglo XIII, donde el anotador de Berna 276 cita dos de sus obras (el De Die Natali de Censorino y el Querolus). Aunque no se sabe nada más de él hasta que aparece en Italia en posesión de Serafino Nibbia de Novara $^{11}$, la infuencia de $\mathbf{V}$ puede trazarse a través de sus descendientes.

A través de una copia del siglo XII que adquirió Petrarca ${ }^{12}$ se aseguró su amplia difusión en el Renacimiento, pues todas las copias humanísticas derivaron del arquetipo de Auxerre ${ }^{13}$. El papel de Petrarca fue fundamental en la difusión de la Cosmographia. Humanistas italianos como Guillaume de Pastrengo (1290-1362), Pier Candido Decembrio (1392-1474) y Domenico Bandino di Arezzo (1335-1418) copiaron, leyeron y transmitieron el texto de Pomponio Mela acompañado de notas de Petrarca ${ }^{14}$. De entre sus lectores, Boccaccio ${ }^{15}$ fue el más beneficiado de su saber geográfico ${ }^{16}$. Además, la Cosmographia también fue objeto de interés para importantes geógrafos del siglo XV

${ }^{7}$ El ms. V contiene una miscelánea de textos que son: el De Die Natali de Censorino [Hultsch (1867: 63-73)], un epítome del De musica de San Agustín [Mai (1828: 116-134)], cuatro sermones anónimos [MAI (1828: 135-144)], el Querolus sive Pseudoaulularia de autor anónimo [RANSTRAND (1951)], el epítome de Julio Paris del Factorum et dictorum memorabilium de Valerio Máximo [KempF (1888:473-591)], los Septem Mira [RIESE (1878: 159)], la Cosmographia de Pomponio Mela, y el De fluminibus fontibus lacubus nemoribus paludibus montibus gentibus per litteras de Vibio Secuestre (también publicado por Riese en 1878). Además el manuscrito contiene diversas ilustraciones.

${ }^{8}$ Los estudios críticos sobre la tradición manuscrita de la Cosmographia afirman que todos los codices recentiores, que son más de cien, derivan de V. Una relación completa de los diferentes manuscritos ha sido realizada por Milham (1981: 319-321). A tenor de los datos que nos proporciona la autora, se puede concluir que la mayoría de los recentiores se remontan siglo XV. De especial importancia es el de la Biblioteca Ambrosiana (H 14 inf) del siglo XIV por tratarse de una copia del ms. que poseyó Petrarca y que hoy en día se encuentra desaparecido. Por otra parte, por el hecho de ser anteriores a la mayoría, son destacables los siguientes manuscritos prerrenacentistas: el de la Biblioteca Laurenciana (Aedili 168. S. Marco 341) del siglo X, el de Monte Cassino (391) del siglo XI, el de la Biblioteca Real de Copenhague (Gl.kgl.S.454) del siglo XII, el Vendôme (189) del siglo XII y el de la Biblioteca Nacional de Nápoles (IV.D.21) del siglo XII o XIII.

9 Rouse (1983: 290-292) en Reynolds (1983).

10 QUADRI (1974: XXXVIII-XLIII).

11 De Gregorio (1997: 282).

12 Billanowich (1956: 340) afirma que Petrarca ya poseía un ejemplar de la Cosmographia en el año 1335. De este ms., hoy perdido, se guarda una copia, conservada en la Biblioteca Ambrosiana (H 14 inf.) que incluye la transcripción de las anotaciones que Petrarca había insertado en los márgenes de su ejemplar.

13 Silberman (2003).

14 Paniagua Aguilar (2006:175)

${ }_{15}$ El conocimiento por parte de Boccaccio del texto de Mela puede seguirse en su Genealogia deorum gentilium. Así, utilizando la edición de Álvarez E IGLESIAs (2007), hemos podido comprobar que los capítulos en los que se hace una mención explícita de Pomponio Mela son los siguientes: I, 13; II, 3; III, 23; IV, 22, 30; V, 6, 25; VII, 13, 21, 51, 57; VIII, 13; IX, 33; X, Pr., 10, 12; XII, 25; XIII, 1, 68, 69.

${ }^{16}$ Explica Bouloux (2011:74-75) que Petrarca prestó muchos de sus libros a Boccaccio en aras de su amistad personal. 
como Guillaume Fillastre ${ }^{17}$ (1348-1428), Sozomeno da Pistoia ${ }^{18}$ (1387-1458), Henricus Martellus ${ }^{19}$ (del que sabemos que trabajó en Florencia de 1480-1496) y Johannes Cochlaeus $^{20}(1479-1552)$, entre otros.

\section{La tradición incunable de la obRa de Mela}

La Cosmographia no se encuentra en el proyecto editorial de los primeros tipógrafos, Schweynheim y Pannatz ${ }^{21}$. Sin embargo, en los años siguientes se revela un interés creciente por el texto de Mela como lo corrobora el hecho de que se imprimiera hasta nueve veces ${ }^{22}$ en época incunable: dos en España (en Valencia y en Salamanca) y siete en Italia (la princeps en Milán y el resto en Venecia). La edición en España de la obra de Mela y su ausencia en otros países, como en Alemania y en Francia, donde la implantación del oficio tipográfico es anterior, evidencia el interés de los editores españoles en la impresión de esta obra de carácter geográfico, en un ambiente coincidente con el aumento de las inquietudes de exploradores y descubridores.

Consideramos de suma importancia la producción de las ediciones incunables de Valencia (1482) y de Salamanca (1498), teniendo en cuenta que en el primer cuarto del siglo XVI no se edita a Mela en talleres tipográficos españoles ${ }^{23}$. Habrán de pasar cuarenta años desde la aparición de la edición salmantina para que un español, Pedro Juan Olivar (Olivarius), publique en París en 1538 un comentario donde hace las correspondencias entre las denominaciones topográficas de la Cosmographia y las empleadas en su época. Unos años más tarde, en 1543, Fernando Núñez de Guzmán elabora una edición crítica de la Cosmographia ${ }^{24}$. Las sustanciosas aportaciones de Pedro Chacón (Ciacconius, 1525-1581) y Pedro Juan Núñez (Nunnesius, 1522-1602) no son difundidas hasta 1748, fecha en la que aparecen en la edición de Gronov (1748). También el egregio Francisco Sánchez de las Brozas (1523-1601) edita dos veces la obra de Mela: en 1574 y 1598. A finales del siglo XVI, en 1582, la edición de Andrés Scoto ofrece por primera vez los lugares paralelos de Mela y Heródoto ${ }^{25}$.

La circulación de los textos de Mela en el siglo $\mathrm{XVI}^{26}$ ha dejado indicios muy significativos en algunas de las bibliotecas cortesanas y eclesiásticas más relevantes de este

17 WOODWARD (2007: 304-305).

18 WOODWARD (2007: 296).

19 WOODWARD (2007: 464).

${ }^{20}$ WoOdWARD (2007: 351).

21 Miglio (1997: 15-32).

22 Tras analizar las bases de datos y los repertorios incunabulísticos más importantes, podemos determinar que son nueve las ediciones realizadas a lo largo de la segunda mitad del siglo XV: la princeps, Milán 1471 (Zarotto), Venecia 1477 (impresor desconocido), Venecia 1478 (Maler, Ratdolt y Löslein), Venecia 1478 (Renner), Venecia 1482 (Ratdolt), Valencia 1482 (Palmart), Venecia 1498 (Pensis), Venecia 1498 (Bevilaqua) y, por último, Salamanca 1498 (Núñez de la Yerva). No obstante, un catálogo incunabulístico cualificado, como es el GW, añade cinco ediciones más con respecto a las nueve identificadas: Milán 1472, Venecia 1473 (Jenson), Venecia 1477 (Maler, Ratdolt y Löslein), Bolonia 1497 (Benedictus Hectoris Faelli) y Venecia 1499 (Bernardinus de Vitalibus). Como hemos podido comprobar, en la mayoría de los casos responden a ediciones espurias.

${ }^{23}$ Así lo hemos podido comprobar en el trabajo de NorTon (1978).

${ }^{24}$ Castigationes in Pomponium Melam, Salamanca, 1543.

25 GuZMÁn Arias (1993: 507-512).

${ }^{26}$ Hernández GonZÁlez (1998: 375-446). 
momento en el que se advierte el interés por incorporar fondos de autores clásicos. Así, el gusto por la obra de Mela se evidencia en los numerosos ejemplares que llenaban las bibliotecas de importantes figuras del ámbito tanto cortesano como eclesiástico de la época ${ }^{27}$, como la de Diego Hurtado de Mendoza $^{28}$, la del marqués de Priego, la de Francisco de Vargas, la del marqués de los Vélez, la de Arias Montano ${ }^{29}$, la del duque de Calabria, la de Juan de Vergara, la de Ponce de la Fuente ${ }^{30}$ y la de Bartolomé Ca$\operatorname{rranza}^{31}$.

En cuanto a las traducciones al español de la Cosmographia, no hay constancia de ninguna en época incunable ${ }^{32}$. Es en los albores del siglo XVI cuando Joan Faras ${ }^{33}$ realiza la primera traducción que conocemos. Habrá que esperar hasta el año 1642 para disponer de la segunda traducción realizada por Luis Tribaldos de Toledo ${ }^{34}$. Con González de Salas ${ }^{35}$, cuya edición es del año 1644 , finalizamos este repaso por las traducciones llevadas a cabo por humanistas hispanos.

En Portugal no se editó la obra de Mela en época incunable, pero la existencia de ejemplares conservados en las bibliotecas lusas deja constancia de la difusión de la que también gozó la Cosmographia en ese país. Es bastante significativo el hecho de que, del total de los seis ejemplares que dichas bibliotecas conservan, tres de ellos sean de la edición de Salamanca ${ }^{36}$. Los ejemplares restantes son de las ediciones venecianas de $1478^{37}$ y de $1482^{38}$.

En España la trascendencia de la difusión de la Cosmographia se evidencia por el elevado número de ejemplares que se conservan actualmente: veinticinco ejemplares, correspondientes a siete de las nueve ediciones incunables. No se halla ningún ejemplar de

27 Quintanilla Raso (1980: 347-384).

28 Diego Hurtado de Mendoza poseyó un ejemplar de la Cosmographia que se encuentra en la Biblioteca del Monasterio de El Escorial. De esta cuestión nos ocuparemos más tarde.

${ }^{29}$ El ejemplar que poseía era el de la edición de Vadiano del año 1518.

30 WAGNER (1979: 35)

31 Tellechea Idígoras (1963: 471-499).

32 Guzmán Arias (1993: 511) y Avenoza (2010).

33 Barradas de Carvalho (1974).

${ }^{34}$ En 1642 se publica en Madrid su obra póstuma La geographía de Pomponio Mela que traduxo del latín al castellano el licenciado Luis Tribaldos de Toledo, cronista mayor de las Indias, ilustrada con notas y con un índice de vocablos.

${ }_{35} \mathrm{Su}$ obra con la traducción de Mela lleva por título Compendio geographico i historico de el orbe antiguo i descripcion de el sitio de la tierra, escripta por Pomponio Mela, español antiguamente en la Republica Romana; $i$ ahaora con nueva y varia ilustracion, restituido a la suia española.

${ }^{36}$ En la Biblioteca Nacional de Portugal se hallan dos incunables (Sig. 504/2 y 505) y en la Biblioteca Pública e Arquivo Distrital de Évora se conserva uno (419). Las referencias en los distintos catálogos son las siguientes: ISTC im00455000; GW M34862; IBPort 1229; Mendes 865, 866.

37 De esta edición de Renner se conservan dos ejemplares: uno en la Biblioteca Pública e Arquivo Distrital de Évora (el incunable 307) y otro en la Biblioteca da Ajuda de Lisboa (con signatura E 48-VIII-14//1). Sus referencias son ISTC im00455000; GW M34862; IBPort 1229; Mendes 865, 866.

${ }^{38}$ Se trata del incunable con signatura 679, ejemplar de la edición de Ratdolt que se encuentra en la Biblioteca Nacional de Portugal y cuyas referencias son: ISTC im00452000; GW M34876; HC 11019; IBP 3690; IBPort 1228; Mendes 864. 
la editio princeps, realizada en Milán en el año $1471^{39}$, así como tampoco de la edición realizada en Venecia en el año $1478^{40}$.

A continuación analizamos los ejemplares conservados en España de las siete ediciones de la Cosmographia.

\section{A. Venecia 1477}

Esta edición vio la luz el 15 de noviembre de 1477 bajo el título Cosmographia, sive De situ orbis ${ }^{41}$. No se conoce el nombre del impresor.

Se trata de una edición que carece de portada y consta de 62 hojas. Está realizada con una sola tipografía romana. El texto presenta forma continuada en la caja de impresión ocupando una extensión de 22 líneas. Los comienzos de los tres capítulos aparecen en blanco. Carece de las apostillas que caracterizan a otras ediciones de esta obra. El colofón cierra el último cuaderno: Pomponii Mellae Cosmographiae liber // explicit. //Venetiis. xv. Nouembris. Mccclxxvii.

En España ${ }^{42}$ se conservan cuatro ejemplares: en la Biblioteca Nacional de Madrid, en la Biblioteca de la Universidad de Barcelona ${ }^{43}$, en el Real Seminario Sacerdotal de San Carlos en Zaragoza y en la Biblioteca Pública del Estado en Ávila.

\section{Madrid, Biblioteca Nacional. Sig. INC/100 (2), olim I-162(2)}

El ejemplar ocupa el último lugar dentro de un volumen facticio ${ }^{44}$. Le faltan las dos últimas hojas. La encuadernación está realizada en pergamino teñido de verde, con hierros y cantos dorados así como con cortes jaspeados.

Procede de la biblioteca del duque de Uceda (1649-1718) que fue incorporada a la Biblioteca Real en $1711^{45}$.

${ }^{39}$ Las referencias en los principales catálogos son las siguientes: im00447000; HCR 11014; Ganda(Zarotus) 2; GW M34861. La editio princeps aparece con el título Cosmographia, sive De situ orbis. Fue impresa el 25 de septiembre de 1471 en Milán por Antonio Zarotto, sobre cuya trayectoria son muchos los datos que conocemos gracias a Ganda (1975). Natural de Parma, en 1471 se trasladó a Venecia donde aprendió el arte de imprimir y donde conoció a Pamfilo Castaldi. A finales de ese mismo año Zarotto y Castaldi crearon una empresa tipográfica en Milán donde, sobre todo, imprimieron obras de clásicos latinos. En 1472 Castaldi abandonó Milán, finalizando así la actividad empresarial entre ambos. De esta edición se conservan ejemplares en Inglaterra, Bélgica, Fracia, Alemania, Italia, Holanda, Austria, Estados Unidos, Dinamarca, Suecia y Rusia.

${ }^{40}$ Las referencias en los principales catálogos bibliográficos son: ISTC im00449000; GW M34875; HC 11016; BSB-Ink P-685. Bernhard Maler (Pictor), Erhard Ratdolt y Peter Löslein fueron los impresores. Rosarivo (1964: 67-172) explica detalladamente la trayectoria de Erhard Ratdolt. Natural de Augsburgo, durante más de diez años (entre 1474 y 1486) vivió en Venecia, donde desarrolló el arte de la impresión y de la tipografía. Se conservan ejemplares de esta edición en Inglaterra, Francia, Alemania, Italia, Holanda, Austria, Estados Unidos, Dinamarca, Suiza y Canadá.

${ }^{41}$ Las referencias son: ISTC im00448000; GW M34865; H 11015; CCPB000111140-X; IBE 3904 (var), 3905; Martín Abad M-92.

${ }^{42}$ Fuera de España, la localización de ejemplares es la siguiente: Inglaterra, Francia, Alemania, Italia, Holanda, Austria, Estados Unidos, Rumanía, Dinamarca, Suecia y Suráfrica.

43 Este ejemplar es una variante de la edición.

${ }^{44}$ Se encuentra encuadernado junto a la obra de Andreas Floccus, De Romanorum magistratibus, realizada en Milán por Filippo da Lavagna entre los años 1475 y 1477.

${ }^{45}$ La biblioteca del IV Duque de Uceda fue una de las colecciones de libros que pasaron a formar parte de la Real Librería de Felipe V cuando éste expropió los bienes de los nobles que apoyaron a su rival durante la Guerra de Sucesión española. 
2. Barcelona, Biblioteca de Reserva de la Universidad de Barcelona. Sig. 07 Inc $544^{46}$

Se trata de un ejemplar cuya encuadernación está realizada en pergamino. En el primer folio aparecen manuscritos el nombre del autor, el título y el capítulo inicial.

Procede ${ }^{47}$ de uno de los conventos desamortizados de la provincia de Barcelona ${ }^{48}$, cuyas bibliotecas pasaron a formar parte en 1835 de la entonces Biblioteca Provincial y Universitaria.

\section{Zaragoza, Biblioteca del Real Seminario Sacerdotal de San Carlos. Sig. E-3-2049}

El ejemplar se encuentra bien conservado, es muy legible y tiene ciertas anotaciones marginales ${ }^{50}$.

Perteneció a Manuel de $\operatorname{Roda}^{51}$ (1708-1782) cuya biblioteca fue legada en memoria testamentaria al Real Seminario ${ }^{52}$.

\section{4. Ávila, Biblioteca Pública. Sig. PA 121/113453}

El ejemplar presenta encuadernación holandesa. Su conservación es bastante buena y no muestra subrayados ni anotaciones. Los cortes están coloreados en azul.

Tiene un exlibris del marqués de Piedras Albas, Bernardino Melgar (1863-1942), quien formó su colección en el último tercio del siglo XIX. Tras su fallecimiento la colección fue comprada por el estado en 1944 e incorporada a la Biblioteca Pública de Ávila.

\section{B. Venecia 1478}

En el año 1478 y en Venecia, Franciscus Renner imprimió la obra que nos ocupa. Su título es el mismo que el de las ediciones anteriores (Cosmographia, sive De situ orbis ${ }^{54}$ ). Franciscus Renner comenzó a imprimir en Venecia en el año $1471^{55}$.

Se trata de una edición carente de portada y realizada con una sola tipografía romana. Presenta un texto continuado dentro de la caja de impresión. Las rúbricas de

46 En el catálogo de la biblioteca realizado por Torra (1995: 293) ocupa el número 492.

${ }^{47}$ Los datos relativos a su procedencia nos han sido proporcionados por responsables de esta biblioteca, D. ${ }^{a}$ Neus Verger y D. ${ }^{a}$ Marina Ruiz, a quien queremos expresar nuestro agradecimiento.

48 A primera vista el lomo parece indicar la procedencia del convento de Sant Josep de Barcelona, de los carmelitas descalzos. No obstante, el catálogo manuscrito de dicha biblioteca, a pesar de recoger la obra, indica una signatura topográfica distinta de la que consta en el ejemplar.

${ }^{49}$ Queremos expresar nuestro agradecimiento a D. Carlos Tartaj, bibliotecario del Real Seminario de San Carlos de Zaragoza, por habernos proporcionado información acerca de este ejemplar.

${ }^{50}$ En el catálogo de Berdejo CASAÑal (1943) figura con el número 51.

51 Marqués de Roda y ministro de Carlos III.

52 En el prólogo de Berdejo Casañal (1943), Luis Sastre se ocupa de esta cuestión.

53 D. ${ }^{a}$ Blanca Asenjo Barahona, responsable de la Biblioteca Pública de Ávila, nos ha proporcionado información sobre este ejemplar, motivo por el cual le estamos muy agradecidos.

${ }^{54}$ Las referencias de los principales catálogos incunabulísticos son: ISTC im00450000; GW M34879; HC 11017*; CCPB000111141-8; IBE 3906; BSB-Ink P-686.

${ }^{55}$ La impresión de la obra de Mela tuvo lugar al año siguiente de su ruptura con el también impresor Nicolaus de Frankordia, con quien había trabajado desde el año 1473. 
los tres libros están realizadas en tinta roja. La edición consta de abundantes apostillas cubriendo los márgenes externos hasta el punto de asemejar una tabla o índice diseminado por toda la obra. El colofón cierra el último cuaderno: Impressum est hoc opusculum Venetiis // per Franciscum renner de Hailbrun. // M. CCC. LXXVIII. // Laus Deo.»

En España ${ }^{56}$ se conservan cuatro ejemplares: en la Real Academia de Ciencias Morales y Políticas de Madrid, en la Biblioteca del Real Monasterio de El Escorial, en la Fundación Bartolomé March de Palma de Mallorca y en la Biblioteca Foral de Bizkaia. El ejemplar de esta última biblioteca no se encuentra registrado en los catálogos incunabulísticos consultados, pero una visita a los fondos digitalizados de dicha biblioteca nos ha permitido descubrirlo.

\section{Madrid, Real Academia de Ciencias Morales y Políticas. Sig. INC-8 ${ }^{57}$}

La encuadernación es de mediados del siglo XIX y está realizada en pasta. Presenta un lomo liso segmentado por filetes dorados así como un tejuelo rojo de dos piezas en el que consta P.MELLA/DE/SIT.ORB y, al pie, RENNER/1478. Sus medidas son: $204 \mathrm{~cm}$. $\times 153 \mathrm{~cm}^{58}$.

El ejemplar pertenece al legado de D. Francisco de Cárdenas ${ }^{59}$, cuya biblioteca llegó a la Academia tras su muerte, acaecida en 1898. Contiene un exlibris en la parte inferior de la primera cara del texto: Aloysius o Luigi Zappelli, canónigo de la basílica de San Marcos de Roma, fallecido en 1901. Se intentó suprimir el exlibris en este y otro ejemplar que perteneció a este mismo canónigo. El ángulo inferior muestra el sello en tinta de la Real Academia privativo de la biblioteca Cárdenas, anotándose la sig. topográfica 13-9-3069. También de mano sobre el ángulo superior consta la inscripción «R.16.626» correspondiente al registro general de la entrada de la biblioteca.

\section{El Escorial, Real Biblioteca del Monasterio. Sig. 14-V-13 ${ }^{60}$}

El ejemplar conserva la encuadernación escurialense del siglo XVI sobre tabla y cortes dorados. Presenta un buen estado general de conservación pese a tener un agujero en la parte inferior de la tapa posterior. Le faltan cuatro folios ${ }^{61} \mathrm{y}$ en algunos otros hay manchas amarillentas ${ }^{62}$. En la vuelta de la portada tiene anotada la signatura

\footnotetext{
${ }^{56}$ Fuera de España, se localizan ejemplares en Inglaterra, Bélgica, Alemania, Italia, Portugal, Holanda, Austria, Estados Unidos, Hungnría, Dinamarca, Suecia, Finlandia, Polonia, Rusia, Praga, Chequia y Japón.

57 Agradecemos a D. Pablo Ramírez, bibliotecario de la Real Academia de Ciencias Morales y Políticas, la información que nos ha proporcionado acerca de este ejemplar.

${ }^{58}$ Estos datos han sido tomados del catálogo de la institución, llevado a cabo por García CraviotTo (2007), en el cual figura con el número 26.

${ }^{59}$ Francisco de Cárdenas fue presidente de la Academia y embajador en el Vaticano durante muchos años. Gran bibliófilo, en Roma adquirió la mayor parte de su colección de incunables.

${ }^{60}$ Agradecemos a D. José Luis del Valle Merino la amabilidad con la que nos ha atendido y las explicaciones que nos ha proporcionado acerca de la encuadernación del ejemplar.

${ }^{61}$ Del 11 al 14.

${ }^{62}$ De los folios 1 al 3; así como en las hojas 47 y 48.
} 
VI-N-13 tachada y una anotación manuscrita («tapadera a») que ha dejado huella de tinta en la primera hoja del ejemplar donde, además, hay otras notas parcialmente cortadas por efecto de la encuadernación. También contiene ciertas páginas enumeradas a mano ${ }^{63}$.

Contiene un exlibris ${ }^{64}$ de Diego Hurtado de Mendoza (1503-1575) ${ }^{65}$ cuya biblioteca ${ }^{66}$, una de las más ricas y escogidas que había en España, pasó a formar parte de la Biblioteca del Monasterio en el año 1576.

\section{Palma de Mallorca, Fundación Bartolomé March. Sig. B107-A-0167}

En primer lugar, conviene hacer una aclaración con respecto a la ubicación del ejemplar. Los principales catálogos incunabulísticos lo sitúan en la Fundación March de Madrid, pero, tras distintas consultas realizadas en dicha institución, supusimos que se trataba de un error ya que el ejemplar no consta en el catálogo de la biblioteca. Finalmente, comprobamos que su localización no es Madrid, sino Palma de Mallorca, concretamente en la Fundación Bartolomé March.

El ejemplar está encuadernado en piel roja y se conserva en buen estado. Por efecto de la encuadernación ha sido guillotinado y su tamaño es de 21,5 cm. Marcas propias del ejemplar son el coloreado manual de las letras capitales de los folios 1 y 34 y el intercalado a lo largo del texto de diversos calderones rojos y negros, también manuscritos, así como algunas apostillas en los márgenes.

En cuanto a su procedencia, el libro fue registrado en la colección de D. Bartolomé March en abril de 1978, lo cual no quiere decir que se adquiriera en esa fecha ${ }^{68}$, puesto que el inicio de la colección se remonta a los años 50 y 60, con la compra de la biblioteca de Medinaceli69 ${ }^{6}$ En el año 1983 el ejemplar se trasladó a Palma de Mallorca, para la exposición «Typus Orbis» ${ }^{70}$, organizada por la Fundación Bartolomé March y desde entonces ha permanecido en la biblioteca de Palma, primero en depósito y luego comprado por la Fundación, en 1987.

${ }^{63}$ Concretamente la 10, 20, 30, 40 y 44.

${ }^{64}$ En el exlibris figura «D. Dio de M» y se encuentra en el interior de la tapa anterior.

65 Diego Hurtado de Mendoza, destacado humanista, dejó en testamento su biblioteca a la de El Escorial. Ortega Monasterio (2000: 49) señala que Hurtado tenía una importante deuda de dinero pendiente con el rey, Felipe II, y dejó sus libros y manuscritos en compensación. También Domingo (2011: 86-87) nos aporta información acerca de la biblioteca de este humanista.

${ }^{66}$ Afirma Antolín (1923: 127-137) que la posición social, cargos diplomáticos, amistades, afición y sabiduría de Hurtado de Mendoza contribuyeron a formar su biblioteca.

${ }^{67}$ Agradecemos a D. Fausto Roldán, director de la Biblioteca Bartolomé March, la información acerca de este ejemplar.

${ }^{68}$ El libro de registro de la Fundación no se empezó a realizar hasta que la colección se hizo muy grande. En él consta con el número 10.233 .

${ }^{69} \mathrm{El}$ ejemplar no posee marcas ni exlibris que puedan hacernos pensar que proceda de la biblioteca de D. Antonio Juan Luis de la Cerda, VII duque de Medinaceli, pero Álvarez Márquez (1988: 254) apunta que Pomponio Mela es uno de los autores que estaban presentes en esta biblioteca.

${ }^{70}$ En ella se expusieron documentos de cartografía y de geografía de los siglos XV, XVI y XVII. 
4. Bilbao, Biblioteca Foral de Bizkaia (Bizkaiko Foru Liburutegia). Sig. INC-1971

Los principales catálogos incunabulísticos no recogen la existencia de este ejemplar. Sin embargo, tras realizar distintas averiguaciones, podemos confirmar su presencia en esta biblioteca.

El incunable, además de completo, se encuentra en excelente estado de conservación, con amplios márgenes de época, sin recortar. La encuadernación es del siglo XV, en media piel gofrada y con nervios sobre tabla, con las guardas nuevas. Sobre la tabla aparecen algunas anotaciones manuscritas referidas a Ernesto Mardelli de Bolonia, quizá algún propietario anterior de la obra.

En cuanto a su procedencia, hemos averiguado ${ }^{72}$ que, a fines del 2009, la Biblioteca Foral de Bizkaia (Bizkaiko Foru Liburutegia) compró el ejemplar a la «Librería Anticuaria Astarloa», sita en Bilbao. Esta última había adquirido el ejemplar en 2008 en la librería barcelonesa «Els Llibres del Tirant», la cual, a su vez, lo había conseguido ese mismo año en subasta pública celebrada en Alemania, en concreto, en la casa de subastas «Zisska \& Schauer» de Múnich.

\section{Venecia 1482}

Erhard Ratdolt (1447-1528) publicó en Venecia el 18 de julio de 1482 la obra de Mela. Esta edición (Cosmographia, sive De situ orbis. Add: Dionysius Periegetes: De

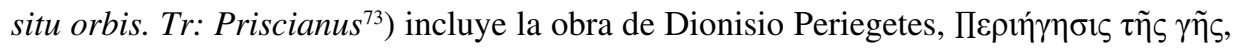
traducida al latín por Prisciano, bajo el título De situ orbis. Es destacable la agrupación de dos obras de carácter geográfico.

La edición carece de portada y presenta las iniciales xilografíadas en rojo y negro. Consta de 48 hojas, comenzando la obra de Dionisio Periegetes a partir de la hoja 30. Presenta título: II Pomponii Mellae Cosmographi Geographia: // Prisciani quoque ex dionysio Thessalonicensi de // situ orbis interpretatio. // Pomponii Mellae de orbis situ Liber primus. Proemium); y colofón: Pomponii melle una cum prisciani ex dionysio de orb- // situ interpretatione finit. Erhardus ratdolt Au- // gusteis impressit Uenetiis. 15. Calen. Augusti An-// no salutis nostre. 1482. Laus deo. Carece de las apostillas propias de otras ediciones de la obra.

Tres son los ejemplares que se conservan en España ${ }^{74}$ : en la Biblioteca Nacional de Madrid, en la Biblioteca de Cataluña y en la Biblioteca Universitaria de Zaragoza.

${ }^{71}$ El ejemplar cuenta con el siguiente enlace permanente: http://www.liburuklik.euskadi.net/handle/10771/11899 (fecha consulta: 26/04/2014).

${ }^{72}$ Queremos expresar nuestro agradecimiento a la técnico de la Bizkaiko Foru Liburutegia (Biblioteca Foral de Bizkaia), D. ${ }^{a}$ Begoñe Madariaga, por la diligencia y apremio con la que ha respondido a nuestras peticiones y por toda la información que nos ha ofrecido amablemente acerca de este ejemplar.

${ }^{73}$ Las referencias son: ISTC im00452000; GW M34876; HC 11019*; CCPB000111143-4; IBE 3908; Martín Abad M-94; BSB-Ink P-687.

${ }^{74}$ Fuera de España se encuentran ejemplares en Inglaterra, Bélgica, Francia, Alemania, Italia, Portugal, Holanda, Estados Unidos, Suiza, Hungría, Dinamarca, Finlandia, Polonia, Rusia, Noruega, Suecia, Israel, Japón, Uruguay, Brasil y Nueva Zelanda. 


\section{Madrid, Biblioteca Nacional, Sala Cervantes. Sig. INC/1545 75}

La encuadernación de este ejemplar es del siglo XIX y está realizada en piel roja, con un marco dorado en ambas tapas, con lomo cuajado y con cantos, contracantos y cortes dorados. Presenta una serie de manchas en la parte superior de las primeras páginas y en la parte inferior hacia la mitad del ejemplar prolongándose hasta el final. Estas manchas tienen aspecto de ser debidas a la humedad. También contiene ciertas marcas de restos de óxido ${ }^{76}$.

El ejemplar perteneció a Fernando José de Velasco y Ceballos (1707-1789) ${ }^{77}$, pasando más tarde a formar parte de la biblioteca del marqués de la Romana, adquirida por la Biblioteca Nacional en el año 1865. Permaneció en el Ministerio de Fomento hasta el año 1873, fecha en la que pasó a estar en la Biblioteca Nacional, como así consta en las Memorias leídas en la Biblioteca Nacional en las sesiones públicas del año 1873.

Este ejemplar es célebre ya que el 6 de septiembre de 2007 sufrió la mutilación del mapa xilografiado de la página inicial. Más tarde se supo que este hecho lo había llevado a cabo César Gómez Rivero en la Sala de Investigadores Miguel de Cervantes ${ }^{78}$.

\section{Barcelona, Biblioteca de Cataluña. Sig. Inc. 22-8 $8^{\mathbf{0 7 9}}$}

El ejemplar está encuadernado en pergamino. Está incompleto ya que le falta el primer folio. Presenta algún rastro de óxido y tiene manchas de humedad en el margen superior. No contiene ninguna anotación marginal ni ningún subrayado.

Fue adquirido por la Biblioteca de Cataluña entre los años 1920 y $1922^{80}$ junto a un gran número de incunables.

75 El ejemplar se encuentra digitalizado y puede consultarse en la página web de la Biblioteca Nacional y en el catálogo de MARTín ABAD (2010:537) figura con la signatura M-94.

${ }^{76} \mathrm{La}$ segunda hoja, en su reverso, presenta un aspecto un tanto sucio. La parte superior de las hojas 3, 4 y 5 están dañadas por un corte en forma de V.

77 Señala Rezábal y Ugarte (1805: 59) que Velasco, gran aficionado a la bibliografía, consiguió reunir en su casa una de las colecciones de libros y papeles más selectas y copiosas. Por su parte, EsCAGEDo (1932: 1) afirma que el catálogo de Velasco está realizado por orden alfabético de autores y reseña unos diez mil ejemplares entre los que cabe destacar una larga relación de incunables y postincunables. Entre su vasta colección se encuentran distintos ejemplares de la Cosmographia: la edición de Valencia de 1482 de Palmart, la de Venecia de 1482 de Ratdolt, la de Salamanca de 1538, dos de París de 1513 y 1551, la de Amberes de 1582, las de Madrid de 1642 y 1644 y la de Lyon de 1748. Según nos cuenta MAYANS y SisCar (1972), tras la muerte de Velasco, sus herederos vendieron su colección de libros a la Biblioteca Nacional, pero otras fuentes nos dicen que esto no fue así. De ANDRÉs (1995:143-146) afirma que su viuda, Paula de Quevedo Hoyos y Colmenares, se deshizo de la colección. Vindel (1934: 36), por su parte, indica que la biblioteca se deshizo en lotes puesto que títulos de su colección aparecen en los catálogos del marqués de la Romana y del marqués de Casa Mena; además escribe que él mismo compró uno de estos lotes en el que, entre otros, estaba la edición de Valencia de 1482 de la Cosmographia.

${ }^{78}$ Distintos medios de comunicación se hicieron eco de esta noticia. Como ejemplo, puede consultarse el periódico El País con fecha de 5 de octubre de 2007.

${ }^{79}$ Hay un enlace permanente a este ejemplar en la siguiente dirección electrónica: http://mdc.cbuc.cat/ cdm/ref/collection/incunableBC/id/55031 (fecha consulta: 26/04/2014).

${ }^{80}$ Así figura en el Boletín de la Biblioteca de Cataluña [Vol. 06 . Años 7-8 , N . 09 (1920-22)]. En este boletín, curiosamente, se detalla el incunable bajo el título de Geographia. A pesar de que en este periodo hubo importantes donaciones a la biblioteca por parte de Eduard Toda (1855-1941) y de Joaquim Miret i Sans (18581918), nuestro ejemplar no figura entre ellas. 
3. Zaragoza, Biblioteca Universitaria. Sig. I $172(5)^{81}$

El ejemplar forma parte de un volumen facticio ${ }^{82}$. Presenta manchas de humedad en el margen superior. No contiene ninguna anotación marginal ni ningún subrayado.

Es difícil concretar en qué momento fue adquirido por la Biblioteca Universitaria de Zaragoza ya que, como afirma Moralejo Álvarez (1998: 284) ${ }^{83}$, no existe un estudio de conjunto de la colección. Pese a que existen distintos materiales que tratan el fondo antiguo universitario zaragozano ${ }^{84}$, no ha resultado posible localizar el momento en el que la obra de Mela pasa a formar parte de dicha biblioteca.

\section{Valencia 1482}

El 18 de marzo de 1482 vio la luz la primera impresión española de la Cosmographia, sive De situ orbis ${ }^{85}$. La llevó a cabo Lambertus Palmart ${ }^{86}$ en la ciudad de Valencia.

El ejemplar carece de portada y presenta texto continuado dentro de la caja de impresión. Tiene 48 hojas y 27 líneas. Los comienzos de los tres capítulos así como de algunos párrafos están en blanco. A lo largo de todo el texto hay abundantes apostillas que cubren los márgenes externos. Presenta colofón donde se indica lo siguiente: Impressum est hoc opusculum in ciuitate // valentie per Lambertum palmart alemanum. // xviii. die mensis marcii. Laus deo. // Anno. M. ccc. lxxxii.

En España ${ }^{87}$ hallamos tres ejemplares: dos en la Biblioteca Nacional de Madrid y uno en la Biblioteca Pública del Estado en Toledo.

${ }^{81}$ El ejemplar se encuentra digitalizado en http://roble.unizar.es/record=b1484321 S1*spi (fecha consulta: 26/04/2014).

${ }^{82}$ Se trata de las siguientes: Libellus de carcere, et alia carmina (de Platinus Platus), Compendium logicae (de Paulus Pergulensis), Passus super universalia Porphirii, superpredicamenta et perihermeneias Aristotelis (de Franciscus de Mayronis), Sphaera mundi. Gerardus Cremonensis. Theoricae planetarum. De motu octavae spherae (de Johannes de Sacro Bosco) y Polyhistor, sive Collectaneae de memorabilibus aut mirabilibus mundi (de Cayo Solino).

${ }_{83}$ Moralejo Álvarez hace un repaso de los incunables de la Biblioteca que merecen especial atención. Hay un grupo de éstos que son únicos en España y que suman un total de 68. Nuestro ejemplar de Mela aparece en este grupo, no por tratarse de una obra única en España (ya que hay otros ejemplares en Madrid y Barcelona), sino porque aparece encuadernado junto a otras obras que no se encuentran en ninguna otra biblioteca española. Se trata del Libellus de carcere, et alia carmina de Platinus Platus, de Passus super universalia Porphirii, superpredicamenta et perihermeneias Aristotelis de Franciscus de Mayronis y de la Sphaera mundi de Sacro Bosco.

${ }^{84}$ Entre estos materiales detacan los Libros de Gestis, que cubren el periodo de 1671 a 1858, el Libro de registro de la Biblioteca Universitaria desde 1856, inventarios diversos, índices, catálogos antiguos, etc.

${ }^{85}$ Las referencias bibliográficas más importantes son las siguientes: ISTC im00451000; GW M34864; HC(Add) 11018; CCPB000111142-6 ; Haeb(BI) 552; Vindel(A) III 30: 13; IBE 3907; Martín Abad M-93.

${ }^{86}$ Museros (2012) indica que el taller de Palmart fue el más importante de todos los que trabajaban en la península ibérica. Palmart, de procedencia alemana (concretamente de la archidiócesis de Colonia) debió instalarse, tras un inicial aprendizaje del oficio, en tierras italianas. Más tarde se trasladó a Valencia llamado por Jacob Vizland, transportando sus propias máquinas impresoras. Tomó asiento definitivo en esta ciudad donde estableció su taller. Se convirtió en un hombre acomodado que alcanzó no sólo el título de «Maestro en las Artes», sino también el cargo de editor del Ayuntamiento de la ciudad de la Diputación del Reino de Valencia. Realizó una magnífica edición de los Fueros de Valencia. Dejó su negocio en el año 1493 fecha en la que vendió cierto número de punzones de letra o matrices. Tras abandonar Valencia, se pierde su pista desconociéndose la fecha y el lugar de su muerte.

${ }^{87}$ Fuera de España, sólo se encuentran algunos ejemplares en Estados Unidos. 


\section{Madrid, Biblioteca Nacional. Sig. INC/366 (olim I-320) $)^{88}$}

La encuadernación de este ejemplar es del siglo XIX. Está realizada en pasta española con hierros dorados en el lomo. En la parte superior del lomo presenta un tejuelo de color verde, lo cual es indicio de haber permanecido algún tiempo separado de la colección de incunables. El ejemplar contiene gran cantidad de manchas de humedad. En la hoja b1 ${ }^{\mathrm{v}}$ presenta un agujero en la línea 25. En la hoja d3 $3^{v}$ hay una importante mancha de óxido que afecta al reverso de d2. El poseedor ha insertado ciertas comas a lo largo del texto ${ }^{89}$. Tiene distintas anotaciones marginales, concretamente a comienzos del Libro I y final del Libro II. Asimismo, presenta subrayados distintos pasajes ${ }^{90}$ y algunos títulos laterales ${ }^{91}$. También es de señalar ciertos trazos verticales en los lados del texto. Por último, a lo largo del texto y compartiendo, en ocasiones, espacio con los subrayados de las líneas y con los trazos verticales, aparecen unos puntos situados en los laterales. Reflexionando acerca de los espacios subrayados, se puede llegar a la conclusión, salvo algunas excepciones, que al lector de este ejemplar le interesaba todo lo que Hispania, Galia e Italia se refiere.

En cuanto a la procedencia de este ejemplar, sabemos que fue adquirido por la $\mathrm{Bi}$ blioteca Nacional en $1863^{92}$.

\section{Madrid, Biblioteca Nacional. Sig. INC-2379 (olim I-1708) ${ }^{93}$}

El ejemplar presenta encuadernación del siglo XIX y está realizada en pergamino con un marco verde, destacado por un filete dorado. Los cantos, contracantos y cortes son dorados. Las hojas en blanco añadidas en la encuadernación presentan filigranas. El ejemplar contiene importantes manchas de humedad, marcas de óxido y de tinta. ${ }^{94}$ La parte superior de $a 1^{v}$ presenta un pequeño agujero. La hoja $f 7^{v}$ en la parte inferior izquierda está dañada. Contiene algunas anotaciones marginales e interlineales. Además presenta líneas subrayadas especialmente en las primeras páginas del ejemplar.

Tiene un exlibris de la Biblioteca de los Caros de Valencia y fue ingresado en la Biblioteca Nacional con la Biblioteca de Pedro Caro y Sureda, III marqués de la Romana. El ejemplar perteneció a Fernando José de Velasco y Ceballos ${ }^{95}$ y su trayectoria es la misma que la del ejemplar de la edición de Venecia 1482 (INC/1545) de la Biblioteca Nacional.

${ }^{88}$ En el catálogo de Martín AbAd (2010:537) responde a la signatura M-93.

89 Como en la línea 13 de la hoja e5 ${ }^{\text {r: }}$ alio ventus, alio unda.

${ }_{90}$ Por citar algunos, cabe destacar aquellos que tienen que ver con Hispania: Columnas Herculis utrumque; Utica et Carthago, ambae inclutae; Valentia; Malaca, etc.

${ }_{91}$ Como Cartago hispanie; Gades insula; Sicilia; Annibal; Corsica; Sardinia; Anas fluuius; Betis; Tagus; Durius; Astures; Cantabri, etc.

En las Memorias leídas en la Biblioteca Nacional en las sesiones públicas de los años 1863 y 1864 (28) figura la adquisición de este ejemplar.

${ }^{93}$ En el catálogo de Martín Abad (210:537) responde a la signatura M-93.

${ }^{94}$ En e4 ${ }^{\mathrm{v}}$ hay una mancha importante de tinta que no afecta al texto.

95 Escagedo (1932). 
3. Toledo, Biblioteca Pública del Estado, Sala Borbón Lorenzana. Sig. INC $12^{96}$

La encuadernación de este ejemplar contiene letras doradas en el lomo. Presenta marcas de humedad así como restos de óxido. Además incluye distintas anotaciones manuscritas marginales y pasajes subrayados. En la página de guarda hay una pegatina en la que figura su signatura ${ }^{97}$.

En cuanto a su procedencia, la casi totalidad de incunables de esta biblioteca procede de la antigua Biblioteca Arzobispal que el cardenal Francisco Antonio de Lorenzana fundó en 1773 en el Palacio Arzobispal de Toledo ${ }^{98}$.

\section{E. Venecia 1498}

En 1498 Christophorus de Pensis publicó en Venecia la Cosmographia, editada por Hermolaus Barbarus ${ }^{99}$ (Cosmographia, sive De situ orbis. Ed: Hermolaus Barbarus ${ }^{100}$ ). Algunos autores han considerado ésta como una de las más importantes ediciones del periodo incunable ${ }^{101}$. Aparte de la obra de Mela, publicó muchas obras de época clásica de autores como Ovidio, Salustio y Vitruvio ${ }^{102}$.

Carente de portada, esta edición es peculiar porque presenta por primera vez un encabezamiento donde se indica el nombre del autor y cada uno de los libros. Consta de 38 hojas y el texto presenta forma continuada repartido en 27 líneas, escrito en tipografía romana. No contiene las apostillas de otras ediciones y finaliza con el colofón siguiente: Pomponii Melae Cosmographi. // Libri Tertii \& Vltimi. // FINIS.

En España ${ }^{103}$ hay dos ejemplares: uno en la Biblioteca General Universitaria de Salamanca y otro en la Biblioteca Capitular y Colombina de Sevilla.

\section{Salamanca, Biblioteca General Universitaria. Sig. BG/37262(2) $)^{104}$}

La encuadernación de este ejemplar está realizada en pergamino con cierres y contiene abundantes anotaciones manuscritas así como pasajes subrayados. Tales anotaciones responden a notas de clase $^{105}$.

${ }^{96}$ El ejemplar se encuentra digitalizado en http://bvpb.mcu.es/es/consulta/registro.cmd?id=397299 (fecha consulta: 26/04/2014).

97 MÉndez APARICIO (1976)

${ }^{98}$ Esta biblioteca fue creada a partir de la Real Cédula de Carlos III, de 17 de febrero de 1771, donde se ordenaba la creación de bibliotecas arzobispales de uso público, utilizando para ello, además de los fondos particulares de los prelados (el propio Cardenal Lorenzana incluyó su biblioteca particular), los fondos de los colegios de los jesuitas que fueron expulsados en 1767.

${ }_{99}$ Hermolaus Barbarus (1454-1493) fue un humanista y crítico de textos italiano. Christophorus de Pensis (de Mandello) fue un impresor que ejerció en Venecia.

${ }^{100}$ Las referencias son las detalladas a continuación: ISTC im00453000; GW M34873; HC 11013*; CCPB000111144-2; IBE 3909; BSB-Ink P-688.

101 Paniagua Aguilar (2006: 175).

102 Hallam (1837: 222-223).

${ }^{103}$ Fuera de España hay ejemplares en: Inglaterra, Bélgica, Francia, Alemania, Italia, Holanda, Austria, Estados Unidos, Hungría, Dinamarca, Suiza, Letonia, Suecia, Polonia y Australia.

${ }^{104}$ El ejemplar figura con el número 473 en el catálogo de la biblioteca realizado por Santander (1990) y está disponible en internet a través del enlace http://gredos.usal.es/jspui/handle/10366/113191 (fecha consulta: 26/04/2014).

105 Carmen Codoñer Merino ha sido la encargada de realizar la ficha bibliográfica de la Cosmographia en el catálogo de Pérez Martín y Becedas González (2012). Codoñer afirma que las anotaciones escolares 
Perteneció a la colección particular de Diego de Covarrubias (1512-1577) ${ }^{106}$, quien legó su biblioteca privada al Colegio Mayor de San Salvador de Oviedo, uno de los antiguos colegios mayores vinculados a la Universidad de Salamanca. A finales del siglo XVIII, con Carlos III y IV, se cerraron los colegios (el de Oviedo en 1797). Aunque el destino de sus bibliotecas fue diverso y accidentado, una gran parte de los impresos fueron a parar a la Biblioteca de la Universidad de Salamanca a principios del siglo XIX ${ }^{107}$.

2. Sevilla, Biblioteca Capitular y Colombina, Sala Hernando. Sig. 12-3-24(1) olim EE-165-14 108

A pesar de que en los principales catálogos incunabulísticos consultados no figura este ejemplar como perteneciente a los fondos bibliográficos de esta biblioteca ${ }^{109}$, podemos afirmar que se conserva en ella ${ }^{110}$.

El incunable ${ }^{111}$ presenta encuadernación en piel labrada sobre tabla, con restos de broches y tejuelo. Contiene anotaciones manuscritas marginales al texto y está encuadernado en un volumen misceláneo.

No contiene ninguna huella que permita identificar su procedencia ${ }^{112}$.

\section{F. Venecia 1498}

Otra edición realizada por Hermolaus Barbarus (1454-1493) fue impresa en Venecia por Simón Bevilaqua en torno al año 1498 bajo el título Cosmographia, sive De situ orbis. Ed: Hermolaus Barbarus ${ }^{113}$. También se encuentra en los repertorios la atribución tipográfica al Taller del «Nomen Jesu». Simón Bevilaqua trabajó, sobre todo, en Venecia; unas pocas obras fueron impresas en Vicenza y una única en Lyon. Publicó a Terencio, Plauto, Cicerón, Tibulo y Ovidio, entre otros.

Esta edición es muy parecida a la también veneciana de 1498 realizada por Cristophorus de Pensis. Así, también presenta encabezamiento, consta de 38 hojas y 27 líneas,

que presenta el incunable se debe a que su lectura era obligatoria en el periodo de aprendizaje de la lengua latina.

106 Pérez Martín y Becedas González (2012).

107 Queremos expresar nuestro agradecimiento a D. ${ }^{a}$ Margarita Becedas González, Directora de la biblioteca General Histórica de la Universidad de Salamanca, por la información que nos ha proporcionado acerca de este ejemplar.

${ }_{108}$ Agradecemos a D. José Francisco Sáez Guillén, Jefe de Sección de Bibliotecas de la Institución Colombina, la información que nos ha proporcionado acerca de este incunable.

109 También lo afirma HaEbler (1903).

${ }^{110}$ Los principales catálogos ofrecen un dato erróneo ya que detallan que el ejemplar que se conserva en esta biblioteca es uno de la edición de Salamanca 1498 de Núñez de la Yerva.

111 En el catálogo de Segura Morera (1999) figura con el número 842.

112 Consultado el Abecedarium B de Hernando Colón (Biblioteca Colombina: 1992), comprobamos que esta edición veneciana de Christophorus de Pensis no está entre las obras que formaron parte de su biblioteca. En el catálogo de De la Rosa (1972: 40) aparece recogido este ejemplar donde se indica que pertenece a la biblioteca Capitular.

${ }^{113}$ Las referencias son: ISTC im00454000; GW M34868; CCPB000111145-0; IBE 3910; Martín Abad M-96. 
su tipografía es romana, no tiene apostillas marginales y el colofón es el siguiente: Pomponii Melae Cosmographi. // Libri Tertii \& Vltimi. // FINIS.

En España ${ }^{114}$, la Biblioteca Nacional de Madrid cuenta con un ejemplar de esta edición en la Sala Cervantes, con signatura INC/974(3), olim I-2280(3) ${ }^{115}$. El incunable presenta alguna anotación, parcialmente cortada con los márgenes, y manchas. La encuadernación es del siglo XVII y está realizada en pergamino. Tiene restos de broches. Ocupa el último lugar dentro de un volumen facticio, precedido de ejemplares de Ptolomeo $^{116}$ y de Higino ${ }^{117}$. Procede de la Biblioteca Real.

\section{G. Salamanca 1498}

En último lugar encontramos la segunda edición española de la obra de Mela ${ }^{118}$. En esta ocasión se trata de la edición de Francisco Núñez de la Yerva ${ }^{119}$, humanista y profesor, realizada en Salamanca el 17 de abril de $1498^{120}$.

Se trata de una edición con portada exenta (Cosmographia pom // ponii cum figuris). Contiene iniciales xilografiadas y el número de líneas oscila entre 27 y 29. Consta de abundantes apostillas al igual que otras ediciones. El colofón cierra el último cuaderno: Opus preclarissimi Pomponii Melle cosmogra // phi cum introdictionibus \& aliis tantopere necessa // riis Per Franciscum nunis de la yerva medicine pro // fessorem elaboratis. Explicit feliciter. Impressum // uero Salmantice (cuius loci elongato aba occiden // ti. ix. et ab equinoctiali. lxj. gradibus constat). // Anno dni. M. ccccxcviii. Sole taure punctum // gradiente primum.)

En España ${ }^{121}$ se conservan ocho ejemplares de esta edición: en la Biblioteca Nacional de Madrid (dos ejemplares), en la Biblioteca del Palacio Real de Madrid, en la Biblioteca General Universitaria de Salamanca, en la Biblioteca Capitular de Toledo, en la Bibliteca General de la Universidad de Sevilla, en la Librería Conventual de San Francisco de Santiago de Compostela (A Coruña) y en el Seminario Diocesano de Girona.

\footnotetext{
114 Fuera de España se localizan ejemplares en Inglaterra, Francia, Alemania, Italia y Estados Unidos.

115 En el catálogo de MARTín ABAD (2010:538) aparece registrado con la signatura M-96.

116 Ptolomaeus, Claudius: Liber de analemmate, a Federico Commandino Vurbinate instauratus \& commentariisillustratus, ...Eiusdem Federici Commandini liber de Horologiorum descriptione. - Roma: Paolo Manuzio, 1562.

117 Hyginus, Caius Julius: De mundi et sphere ac utriusque partium declaratione cum planetis et variis signis historiatis. - Venezia: Guivanni Battista Sessa, 25 VIII 1502.

${ }^{118}$ Las referencias en los distintos catálogos son las siguientes: ISTC im00455000; GW M34862; CCPB000111146-9; HCR 11021; Haeb(BI) 553; Haeb(GSpF) p. 418; Vindel(A) II 148: 95; IBE 3911; Martín Abad M-95.

119 Peset (1989: 379).

${ }^{120}$ En los distintos catálogos de incunables consultados figura que el impresor es el mismo que el de la Gramática Castellana de Antonio de Nebrija. En el catálogo de MARTín ABAD (2010: 537) aparece como impresor Juan de Porras. Salamanca fue una de las primeras ciudades con imprenta. Allí se establecieron impresores alemanes y lombardos como John Hust y Juan de Porras hacia 1480. González Vega (2002: 90) explica que Porras, más que un activo impresor, fue un poderoso librero encargado de financiar las ediciones a sus expensas. Brasil.

${ }^{121}$ Fuera de España hay ejemplares en Inglaterra, Bélgica, Alemania, Italia, Portugal, Estados Unidos y
} 
1. Madrid, Biblioteca Nacional, Sala Cervantes. Sig. INC/350 olim I-304(1) ${ }^{122}$

La encuadernación del incunable está realizada en pergamino, con cortes rojos y es del siglo XX. El ejemplar presenta distintas zonas subrayadas y anotaciones marginales e interlineales, parcialmente cortadas con los márgenes, en letra de la época. Ocupaba el primer lugar dentro de un volumen facticio ${ }^{123}$.

Por lo que se refiere a su procedencia, en la portada hay una anotación en la que se indica que es del «Colegio de S. Thomas de Valencia». En una hoja de guarda delantera una anotación manuscrita, simulando un exlibris, dice: «Don Fernando Casado de Torres».

\section{Madrid, Biblioteca Nacional, Sala Cervantes. Sig. INC/1631 olim I-1683 $3^{124}$}

La encuadernación del ejemplar es del siglo XX, gofrada en piel. Presenta zonas subrayadas y anotaciones marginales e interlineales, parcialmente cortadas con los márgenes, en letra del siglo XVI. Forma parte de un volumen facticio, en el que ocupaba el segundo y último lugar ${ }^{125}$. En la última hoja se repite el nombre de «Antonio Rodríguez» $^{126}$.

Fue adquirido por la Biblioteca Real el 30 de diciembre de 1739.

Al igual que el INC/1545, correspondiente a la edición de Venecia de 1482 de Ratdolt, este ejemplar también fue objeto de mutilación en el año 2007 por parte de César Gómez Rivero ${ }^{127}$.

\section{Madrid, Biblioteca del Palacio Real. Sig. I/141 olim I-A-7}

La encuadernación es del siglo XIX ${ }^{128}$ y está realizada en pasta valenciana marrón con orla dorada en ambas caras ${ }^{129}$. El lomo consta de hierros dorados y tejuelo en piel roja. Presenta cantos dorados, cortes jaspeados y guardas de aguas. Contiene anotaciones y apostillas manuscritas y carece de algunas hojas ${ }^{130}$.

122 En el catálogo de Martín ABAD (2010:538) se le identifica con la signatura M-95.

${ }^{123}$ La Cosmographia estaba seguida de ejemplares de Tomás Brawardino (Arithmetica) y de Nebrija (Aelij Antonij Nebrissensis Relectio nona de accentu latino aut latinitate donato quam habuit Salmantice). Estos ejemplares están hoy en día desprendidos del volumen facticio; el de Brawardino actualmente presenta la signatura topográfica R-24569 y el de Nebrija se halla en paradero desconocido.

${ }^{124}$ En el catálogo de MARTín ABAD (2010: 538), la signatura que le corresponde es M-95.

${ }^{125}$ El primer lugar de este volumen estaba ocupado por el Fasciculus temporum de Rolevinch y Werner, que ocupaba la signatura topográfica I-2366 y que hoy en día está desaparecido.

126 Martín Abad (2010: 538) indica que este nombre no se debe corresponder con el de ningún poseedor.

127 En este caso, Gómez Rivero mutiló la quinta hoja que fue devuelta el 13 de diciembre de 2007. Posteriormente se procedió a fijar la hoja arrancada.

128 López Serrano (1989).

129 La ficha bibliográfica de este ejemplar se encuentra en la siguiente dirección: http://realbiblioteca.patrimonionacional.es/cgi-bin/koha/opac-detail.pl?biblionumber=84154 (fecha consulta: 26/04/2014).

${ }^{130}$ La 1 y la 4. 
El ejemplar perteneció al infante Antonio de Borbón, duque de Calabria y hermano de Carlos IV ${ }^{131}$ (1747-1777). Contiene un exlibris real de Carlos IV (1748-1819) y Fernando VII (1784-1833) así como una etiqueta del encuadernador ${ }^{132}$.

\section{Salamanca, Biblioteca General Universitaria. Sig. BG/I. 184(1) olim 2-12-8-19133}

El ejemplar, encuadernado en pergamino, ocupa el primer lugar dentro de un volumen facticio ${ }^{134}$. Contiene abundantes anotaciones manuscritas de carácter escolar ${ }^{135}$. que evidencian la utilización del ejemplar en el ámbito escolar.

Procede de la Compañía de Jesús de Salamanca, como así lo atestigua el exlibris, manuscrito y tachado, de la portada. Además, en la cubierta contiene un exlibris de la biblioteca de la Universidad de Salamanca.

\section{Toledo, Catedral, Archivo y Biblioteca. Sig. BCT 77-23(1) $)^{136}$}

La encuadernación está realizada en pasta española y, junto a otras dos obras, forma parte de un volumen facticio ${ }^{137}$. Presenta notas marginales e interlineales ${ }^{138}$.

Se trata de una obra procedente del «Antiguo Fondo Toledano» que contiene los libros que han estado en la biblioteca desde una época anterior a finales del siglo XVIII, cuando llegan los otros dos fondos, «Zelada» y «Lorenzana», de manera que contamos con un término ante quem que acredita la presencia de la obra en este fondo con anterioridad al siglo XVIII.

\section{Sevilla, Biblioteca General de la Universidad. Sig. A 335/022 $2^{139}$}

El ejemplar se encuentra en buen estado y su encuadernación está realizada en pergamino sobre cartón. El abundante número de anotaciones marginales que posee nos lleva a pensar que este ejemplar fue usado como material escolar, al igual que los ejem-

131 Bouza (1990: 115) afirma que el sello que tiene pegado con las iniciales «S.D.S.Y.D.A.» indican el ejemplar perteneció al infante Antonio de Borbón, duque de Calabria y hermano de Carlos IV.

${ }^{132}$ En la etiqueta se indica lo siguiente: «Martin encuadernador de Cámara de SS.MM. y AA. lo encuadernó calle del Espejo n. ${ }^{\circ} 11$ Madrid»

${ }^{133}$ El ejemplar está digitalizado en http://brumario.usal.es/record=b1452102 S1*spi (fecha consulta: 26/04/2014).

${ }^{134}$ Está encuadernado junto al comentario de Nebrija a esta obra (c. 1498) y a la Repetitio sexta de Nebrija del año 1510.

135 Al igual que en el ejemplar conservado en la Universidad de Salamanca de la edición de Venecia de 1498 de Cristophorus de Pensis, las anotaciones manuscritas de este ejemplar tienen un carácter claramente escolar. Así, conviene recordar lo que sobre aquél indica la profesora Codoñer en el catálogo de PÉREZ MARTín y BECEDAs GoNZÁLEZ (2012) acerca de la obligatoriedad de la lectura de la obra de Mela en el periodo de aprendizaje de la lengua latina.

136 Agradecemos a D. Alfredo Rodríguez González, técnico del Archivo y Biblioteca Capitulares de Toledo, la información proporcionada acerca de este ejemplar.

${ }^{137}$ Se trata de una obra de Nebrija publicada en Salamanca en el año 1502, Aelii Antonii nebrissensis in uafre discta philosorum.

138 En el catálogo de Méndez Aparicio (1976) figura con el número 4.

139 El ejemplar figura con el número de asiento 158 en el catálogo de IsASI-IsASMENDI (1967) y se encuentra digitalizado en http://fama.us.es/record=b1514399 S1*spi (fecha consulta: 26/04/2014). 
plares que conserva la Universidad de Salamanca de las ediciones de Venecia de 1498 de Cristophorus de Pensis y de Salamanca de 1498 de Núñez de la Yerva.

Procede del Colegio de San Hermenegildo de la Compañía de Jesús de Sevilla. Los libros de este colegio pasaron a ser custodiados por la Biblioteca de la Universidad de Sevilla con motivo de la expulsión de la Compañía en el año 1767.

\section{Girona, Biblioteca Diocesana del Seminario. Sig. I/6 $6^{140}$}

El ejemplar presenta una encuadernación realizada en pergamino y está incompleto ya que le faltan los últimos folios. Ocupa el primer lugar dentro de un volumen facticio, seguido de la obra Opuscula, impresa en Burgos en 1512 en el taller de Federico Alemán.

El ejemplar perteneció ${ }^{141}$ a Martín Matute y Pérez de Tobía (1781-1868), quien lo legó a la biblioteca del Seminario ${ }^{142}$.

8. Santiago de Compostela, Librería Conventual de San Francisco. Sig. 34-2-24 ${ }^{143}$, olim 17705-34-5-7

El ejemplar ${ }^{144}$, que se encuentra en buen estado, forma parte de un volumen facticio junto a obras de Tomás de Aquino ${ }^{145}$, de Pedro de Castrovol ${ }^{146}$, de Julián Gutiérez ${ }^{147}$ y de Aristóteles ${ }^{148}$.

\section{Conclusiones}

Con este estudio hemos pretendido demostrar que la obra de Pomponio Mela tuvo amplia difusión en España a tenor del patrimonio incunable conservado: veinticinco ejemplares, correspondientes a siete de las nueve ediciones.

El análisis de este conjunto de ediciones y ejemplares nos ha revelado que la divulgación del texto de Mela en los siglos XV y XVI se debió al interés por la geografía antigua y a la utilización como herramienta escolar, razones avaladas por la presencia de la Cosmographia en las estanterías de bibliófilos nobles y eclesiásticos, sobre todo del siglo XVI, como Diego Hurtado de Mendoza, Francisco de Vargas, Arias Montano y Bartolo-

\footnotetext{
${ }^{140}$ Se puede acceder a la ficha bibliográfica en el siguiente enlace: http://cataleg.udg.edu/record=b1282585 (fecha consulta: 26/04/2014).

${ }^{141}$ La información sobre este ejemplar nos ha sido proporcionada por D. Albert Serrat, archivero del Archivo Diocesano de Girona, al cual queremos expresar nuestro agradecimiento.

${ }^{142}$ El ejemplar contiene una anotación manuscrita en la que se puede leer: «El Iltre Sor Dn...Matute Arcediano de la Catedral al Seminario Conciliar de Gerona».

${ }_{143}$ Agradecemos a D. Santiago Cepeda, responsable de la Librería Conventual, la información proporcionada acerca de este ejemplar.

${ }^{144}$ En el catálogo de CANTelar Rodríguez (1978) figura con el número de asiento 51.

${ }^{145}$ De esse et essentiis tum realibus tum intentionalibus, cura Ludovici de Righis. Venetiis, Iohannes Lucilius Santritter et Hieronymus de Sanctis expensis Francisci Bollani XIX Kalendas Martii (dic) 1488.

146 Formatilites breves. Pampilonae, Arnaldus Guillen de Brocario, circa 1496.

${ }^{147}$ De Julián Gutiérrez hay dos obras: una es De computationes dierum criticarum, Toleti, Antonius Tellez, 28 Martii 1495; y otra, De potu in lapidis praeseruatione, Toleti [Antonius Tellez], 29 Martii 1494.

${ }_{148}$ Auctoritates (Propositiones Universales) Aristotelis et aliorum philosophorum, Venetiis, Paganinus de Paganini, circa 1495.
} 
mé Carranza, entre otros ${ }^{149}$, así como por su uso con fines didácticos para el aprendizaje de la lengua latina. En este sentido, hemos detectado, por un lado, un grupo de ejemplares que apenas contienen anotaciones manuscritas, como es el caso del ejemplar de la edición de Venecia 1478 de Renner que se encuentra en la Biblioteca del Monasterio de El Escorial o el de la edición de Valencia de 1482 de Palmart de la Biblioteca Nacional (INC-2379), los cuales evidencian haber sido adquiridos para uso personal. Por otro lado, hemos advertido la presencia de ejemplares que, debido a sus copiosos apuntes, demuestran haber sido utilizados con fines académicos, como es el caso del de la edición de Salamanca 1498 de Núñez de la Yerva que se conserva en la Biblioteca General de la Universidad de Sevilla o del de la edición de Venecia 1498 de Cristophorus de Pensis que se halla en la Biblioteca General Universitaria de Salamanca ${ }^{150}$.

Asimismo resulta de particular relevancia que la obra de Mela esté presente en bibliotecas de destacados humanistas como Diego Hurtado de Mendoza cuyo ejemplar de la edición de Renner de 1478 se conserva casi intacto ${ }^{151}$ en la Real Biblioteca del Monasterio de El Escorial, donde permanece desde el siglo XVI ${ }^{152}$. De la mayoría de ejemplares restantes podemos seguir su trayectoria desde el siglo XVIII, si bien de un nutrido grupo tenemos noticia desde los siglos XIX y XX.

Así mismo, el análisis abordado en este estudio nos ha permitido detectar errores en la catalogación ${ }^{153}$ de este fondo de incunables. Es el caso de un ejemplar que se encuentra en la Biblioteca Capitular y Colombina de Sevilla. La información que nos proporcionan los catálogos es que se trata de la edición de Salamanca de 1498 de Núñez de la Yerva, tratándose, en realidad, de la edición de Venecia de 1498 de Cristophorus de Pensis. Otro es el caso del ejemplar de la edición de Venecia de 1478 de Renner al que los catálogos lo sitúan en la Fundación March de Madrid. La localización es errónea ya que el ejemplar se encuentra en Palma de Mallorca, en la Fundación Bartolomé March Servera.

Ha sido especialmente significativo el hallazgo de un ejemplar que, hasta este momento, no está recogido en ningún catálogo de referencia sobre incunables (salvo en el de la propia biblioteca ${ }^{154}$ ) por ser de reciente adquisición: el de la edición de 1478 de Renner conservado en la Biblioteca Foral de Bizkaia.

149 Hernández GonZÁLez (1998: 375-446).

150 Codoñer, en Pérez Martín y Becedas González (2012), afirma, a propósito del ejemplar de la edición de Venecia de 1498 de Cristophorus de Pensis (con sign. BG / 37262) conservado en la Universidad de Salamanca, que la lectura de la obra de Mela era obligatoria en el periodo de aprendizaje de la lengua latina.

${ }^{151}$ La encuadernación del ejemplar no es la característica de Hurtado de Mendoza sino la escurialense del siglo XVI.

${ }^{152}$ La biblioteca de Diego Hurtado de Mendoza (1503-1575) fue una de las más importantes de su época y pasó a formar parte de la Real Biblioteca tras su muerte, como pago de unas deudas que tenía con Felipe II.

153 Como ya hemos dicho con anterioridad, los catálogos incunabulísticos manejados han sido el CCPBE, el GW y el ISTC.

154 Biblioteca Foral de Bizkaia (2011) 


\section{BIBLIOGRAFÍA}

A. I., 1874: «Inventario de los libros del Duque de Calabria (1550)» en Revista de Archivos, Bibliotecas y Museos, 4, Madrid.

Alonso Turienzo, T., 1974: Índice de incunables de la Real Biblioteca del Escorial y Biblioteca de la Comunidad de PP. Agustinus, S. Lorenzo de El Escorial.

Álvarez Márquez, M. C., 1988: «La biblioteca de Don Antonio Juan Luis de la Cerda, VII Duque de Medinaceli, en su palacio del Puerto de Santa María (1963)» en Historia. Instituciones. Documentos, n. ${ }^{\circ} 15,251-390$.

Álvarez, M. C. e Iglesias, R. M., 2007: Los quince libros de la genealogía de los dioses paganos. Giovanni Boccaccio, Madrid.

Antolín, G., 1923: Catálogo de los códices latinos de la Real Biblioteca del Escorial, V, Madrid.

Arellano De Córdoba, A., 2000: «El patrimonio bibliográfico de Castilla-La Mancha, un rico legado» en Anaquel n. ${ }^{\circ}$ 8, Toledo.

Avenoza Vera, G., 2010: «Traducciones, público y mecenazgo (Castilla, siglo XV)» en Romania $128,452-500$.

Barlow, C. W., 1938: «Codex Vaticanus Latinus 4929», Memoirs of the American Academy in Rome, 87-124.

Barradas de Carvalho, J., 1974: La traduction espagnole du «De situ orbis» de Pomponius mela par Maître Joan Faras et les notes marginales de Duarte Pacheco Pereira, Lisboa.

Beceiro Pita, I. y Franco Silva, A., 1985: «Cultura nobiliar y biblioteca» en Historia. Instituciones. Documentos, Sevilla.

Berdejo Casañal, E., 1943: Manuscritos e Incunables de la Biblioteca del Real Seminario de San Carlos, Zaragoza.

Biblioteca Colombina, 1992: Hernando Colón. Abecedarium B y Supplementum: Ed. facsímil de los manuscritos conservados en la Biblioteca Colombina de Sevilla, Sevilla.

Biblioteca Foral De Bizkaia, 2011: Bizkaiko Foru Liburutegiaren inkunableak. Incunables de la Biblioteca Foral de Bizkaia, Bilbao.

Billanovich, G., 1956: «Dall' antica Ravenna alle Biblioteche umanistiche», Aevum 30, 319-335.

- 1953: I primi umanisti e le tradizione dei classici latini, Friburgo. Boletín de la Biblioteca de Cataluña. 06 . Años 7-8 , N. 09 (1920-22).

Bouloux, N., 2011: «Pétrarque et les marges des manuscrits géographiques» en Brock, M. (ed.), La bibliothèque de Pétrarque, Brepols, 61-76.

BouzA, A., 1990: El Ex-Libris. Tratado general. Su historia en la corona española, Madrid.

Burke, P., 2000: El renacimiento europeo, Londres.

Cameron, A., 2011: The Last Pagans of Rome, Oxford.

Cantelar Rodríguez, F., 1978: Catálogo de incunables de las bibliotecas del Convento de Franciscanos y del Seminario Diocesano de Santiago, Santiago de Compostela.

Catálogo Bibliográfico Marqués de la Romana, Madrid 1865.

Chevalier, M., 1976: Lectura y lectores en la España de los siglos XVI y XVII, Madrid.

CionI, A., 1994: «Benedetto Faelli» en Dizionario biografico degli Italiani, Roma.

De ANDRÉs, G., 1995: «La biblioteca manuscrita del camarista de Castilla Fernando José de Velasco en la Biblioteca Nacional», en Cuadernos de investigación histórica (seminario Cisneros) 16, Madrid, 143-166.

De Gregorio, V., 1997: Bibliologia e critica dantesca, Rávena.

De la Rosa, S., 1972: Biblioteca Colombina. Catálogo de sus libros impresos, Sevilla.

Domingo Malvadi, A., 2011: Bibliofilia Humanista en tiempos de Felipe II, Salamanca.

Dugan, M. K., 1992: Italian Music Incunabula: Printers and Types, Los Ángeles.

Eisenstein, E., 1994: La revolución de la imprenta en la Edad Moderna europea (vers. esp.), Madrid. 
Escagedo, M., 1932: La Biblioteca del Camarista de Castilla Don Fernando José de Velasco y Ceballos, Santander.

GANDA, A., 1975: «Antonio Zarotto di Parma, tipografo in Milano (1471-1507)» en La Bibliofilia $77,167-222$.

García Craviotto, F., 1989: Catálogo general de Incunables en bibliotecas españolas, Madrid.

- 2007: Colección de incunables de la Real Academia de Ciencias Morales y Políticas, Madrid.

Gautier Dalché, P., 2007: «The Reception of Ptolemy's Geography (End of the Fourteenth to Beginning of the Sixteenth Century» en Cartography in the European Renaissance, Chicago.

Gil Fernández, L., 2005: «Los Studia Humanitatis en España durante el reinado de los Reyes Católicos» en Península. Revista de Estudios Ibéricos 2, 45-68.

González Vega, F., 2002: Aurelii Prudentii Clementis V. C. libelli: cum commento Antonii Nebrissensis, Salamanca.

Gronov, J., 1748: Pomponii Melae de Situ orbis Libri III, cum notis integris Herm. Barbari, Petri Ioannis Olivarii, Fredenandi Nonii Pintiani, Petri Ciacconii, Andreae Schotti, Isaac Vosii, et Jacobi Gronovii. Accedunt Petri Joannis Nunnesii epistola de Patria Pomponii Melae, et adnotata in proemium, atque duo priora capita libri I et Jacobi Perizonii adnotata al libri I capita septendecim curante Abraham Gronovio, Leiden.

Guzmán Arias, C., 1993: «La obra de Pomponio Mela en el Humanismo hispano» en Maestre Maestre, J. M. y Pascual Borea, J. (coord.): Humanismo y pervivencia del mundo clásico: actas del I Simposio sobre Humanismo y pervivencia del mundo clásico, 1, 507-512, Alcañiz.

Guzmán Arias, C., 1989: Pomponio Mela, Corografía, Murcia.

HAEBLER, K., 1903: Bibliografía ibérica del siglo XV, La Haya.

- 1896: The Early Printers of Spain and Portugal, Londres.

Hain, L., 1826: Repertorium Bibliographicum, París.

Hallam, H., 1837: Introduction to the Literature of Europe, I, Londres.

Hernández González, M. I., 1998: Suma de inventarios de Bibliotecas del siglo XVI (15011560), en López-Vidriero, M. L. y CÁtedra, P. M.: El libro antiguo español IV. Coleccionismo y Bibliotecas (Siglos XV-XVIII), Salamanca.

Hidalgo, D., 1861: Boletín Bibliográfico Español, II, Madrid.

Hulstch, F., 1867, Censorini de Die Natali Liber, Leipzig.

IsASI-IsASMENDI, J., 1967: Catálogo de incunables de la Biblioteca Universitaria, Sevilla.

KemPF, C., 1888: Valerius Maximus, Leipzig.

KRAYE, J., 1998: Introducción al humanismo renacentista (vers. esp.), Madrid.

LAmarca Langa, G., 2002: «Las fuentes del erudito. Las bibliotecas zaragozanas en el último tercio del siglo XVIII» en Bulletin Hispanique, 104, n. ${ }^{\circ}$ 1, 215-242.

Laspéras, J. M., 1976: «La librería del doctor Juan de Vergara», en Revista de Archivos, Bibliotecas y Museos 79, Madrid.

Lestringant, F., 1991: L'atelier du cosmographe, París.

López Serrano, M. y García Morencos, P., 1989: Incunables, Madrid.

Lowry, M., 1994: «Nicholas Jenson and the Rise of Venetian Publishing in Renaissance Europe» en The Journal of Modern History, 66, 2, Chicago.

MaI, A., 1828: Scriptorum Veterum Nova Collectio, Roma.

Martín Abad, J., 2010: Catálogo bibliográfico de la colección de incunables de la Biblioteca Nacional de España, I, Madrid.

- 2003: Los primeros tiempos de la imprenta en España (c. 1471-1520), Madrid.

Martínez de Sousa, J., 1987: Pequeña historia del libro, Barcelona.

Mayans y Siscar, G., 1972: Epistolari. Volumen XVI : Mayans y los altos cuadros de la Magistratura y Administración borbónica, 3. Fernando José de Velasco Ceballos (1753-1781), Oliva. 
Memorias leídas en la Biblioteca Nacional en las sesiones públicas de los años 1863 y 1864, Madrid 1870.

MÉndez, F., 1861: Tipografía española, Madrid.

Méndez Aparicio, J., 1976: Catálogo de los incunables de la Biblioteca Pública de Toledo: colección Borbón-Lorenzana, Toledo.

Menéndez Pelayo, M., 1902: Bibliografía hispano-latina clásica, Madrid.

Mestre Sanchís, A., 2007: Los ilustrados, el origen de la imprenta y el catálogo de incunables españoles, Valencia.

Miglio, M., 1997: «La diffusione della cultura umanistica negli incunaboli: Roma», en Accademie e biblioteche d'Italia, 65, Roma.

MiLANeSI, M., 1994: «Geography and cosmography in Italy from the XVth to the XVIIth century» en Memorie della Società Astronomia Italiana, 65, Pavía.

Milham, M. E., 1973: «An Introduction to the Renaissance Tradition of Pomponius Mela» en Acta conventus neo-latini Amstelodamensis, Amsterdam, 786-793.

- 1981: «A ms inventory of Pomponius Mela» en Scriptorium: revue internationale des études relatives aux manuscrits, 35, 2, 319-321.

- 1980: «Oporimus, Olivarius and Pomponius Mela» en Basler Zeitschrift für Geschichte und Altertumskunde, 80, 133-143.

Moralejo Álvarez, M. R., 1998: «La colección histórica de la Biblioteca Universitaria de Zaragoza» en El libro antiguo en las bibliotecas españolas, Oviedo.

Moreno Hernández, A. y Ayuso García, M., 2013: «La evolución de la concepción editorial de los primeros impresos incunables y postincunables de la obra de Marciano Capela (14991599)» en Dialogues d'histoire ancienne 39/1, 121-174.

- 2010: «Recepción textual y literaria de la obra de Julio César: bases bibliográficas para el estudio de su pervivencia en España». En ID. (Coord.) Julio César: textos, contextos y recepción. De la Roma Clásica al mundo actual (pp. 529-558), Madrid.

- 2006: «La edición de los Commentarii de César de Venecia, 1511: ¿emendatio original o mera copia?» en Epos, 22, 21-37.

- 2004-2005: «La edición de Philippo de Giunta del Bellum Gallicum de César» en Epos, 20$21,13-30$.

— 2002: «La edición incunable del Bellum Gallicum de Julio César (Burgos 1491)» en Cuadernos de Filología Clásica. Estudios Latinos, 22, 9-42.

Museros, J. V., 2012: «El taller de imprenta de Lambert Palmart» en Real Academia de Cultura Valenciana, Valencia.

Norton, F. J., 1978: La imprenta en España, Madrid.

Ortega Monasterio, M. T., 2000: «La biblioteca de El Escorial: sus fondos hebreos» en AzcáRRAGa Servet, M. J., El manuscrito hebreo bíblico G-II-8, Madrid.

Paniagua Aguilar, D., 2006: El panorama literario técnico-científico en Roma (S I y II d. C.) «Et docere et delectare», Salamanca.

PANZeR, G., 1795: Annales typographici, Nuremberg.

Pérez Martín, I. y Becedas González M. (coords.), 2012: Diego de Covarrubias y Leyva, el humanista y sus libros. Salamanca.

Peset, J. L., 1989: «Relaciones científicas y culturales entre España y América» en Ciencia, vida y espacio en Iberoamérica: Trabajos del Programa Movilizador del C.S.I.C, I, Madrid.

Quintanilla Raso, M. C., 1980: «La biblioteca del marqués de Priego (1518)», en En la España medieval 1, Madrid.

QUADRI, R., 1974: Anonymi Leidensis de situ orbis libri duo, Padua.

RANSTRAND, G., 1951, Querolus sive aulularia: incerti auctoris comoedia una cum indice verborum, Götenborg. 
Redgrave, G., 1894: Erhard Ratdolt and His Work at Venice, Londres.

Reynolds, L. D. (Ed.), 1983: Texts and Transmision. A Survey of the Latin Classics, Oxford.

Rezábal y Ugarte, J., 1805: Biblioteca de los escritores que han sido individuos de los seis colegios mayores, Madrid.

RiESE, A., 1878: Geographi Latini Minores, Heilbronn.

Rodríguez MoÑino, A., 1928: «La biblioteca de Benito Arias Montano. Noticias y documentos para su reconstrucción (1548-1598)» en Revista del Centro de Estudios Extremeños 2, Badajoz.

Rouse, R. H., 1983: «Julius Paris. Epitome of Valerius Maximus; Pomponius Mela. De Chorographia; Vibius Sequester. De fluminibus» en Reynolds, L. D. (Ed.), Texts and Transmision. A Survey of the Latin Classics, Oxford.

Rosarivo, R. M., 1964: Historia general del libro impreso, Buenos Aires.

Samaran, Ch., 1969: «Les écritures de Pétrarque» en Journal des Savants, París, 65-73.

Santander, T., 1990: Catálogo de los incunables existentes en la Biblioteca Universitaria de Salamanca: suplemento, Salamanca.

Segura Morera, A. et alii, 1999: Catálogo de incunables de la Biblioteca Capitular y Colombina de Sevilla, Sevilla.

Serra i Oliveres, A., 1852: Manual de la tipografia española, Madrid.

Silberman, A., 2003: Pomponius Mela, Chorographie, París (reimp. de la 1. a ed. de 1988).

Tellechea Idígoras, I., 1963: «La biblioteca del arzobispo Carranza» en Hispania Sacra 16, Madrid.

Torra, J., y Lamarca, M., 1995: Catàleg dels incunables de la Biblioteca de la Universitat de Barcelona, Barcelona.

VAlENZIANi E. et alii, 1943-1981: Indice generale degli incunaboli delle biblioteche d'Italia, Roma.

VINDEL, F., 1935: Incunables impresos en España en la BN, Madrid.

- 1934: Los bibliófilos y sus bibliotecas: desde la introducción de la imprenta en España hasta nuestros días, Madrid.

Wagner, K., 1979: El doctor Constantino Ponce de la Fuente. El hombre y su biblioteca, Sevilla.

- 1976: «La biblioteca del Dr. Francisco de Vargas, compañero de Egidio y Constantino» en Bulletin Hispanique 78, Burdeos.

Woodward, D., 2007: Cartography in the European Renaissance, Chicago. 